\title{
Honoré de Balzac, Il Padre Goriot
}

\section{Marco Stupazzoni}

\section{(2) OpenEdition}

\section{Journals}

\section{Edizione digitale}

URL: http://journals.openedition.org/studifrancesi/495

DOI: 10.4000/studifrancesi.495

ISSN: 2427-5856

\section{Editore}

Rosenberg \& Sellier

\section{Edizione cartacea}

Data di pubblicazione: 1 aprile 2015

Paginazione: 160

ISSN: 0039-2944

\section{Notizia bibliografica digitale}

Marco Stupazzoni, « Honoré de Balzac, II Padre Goriot », Studi Francesi [Online], 175 (LIX | I) | 2015,

online dal 01 avril 2015, consultato il 17 septembre 2020. URL : http://journals.openedition.org/ studifrancesi/495; DOI : https://doi.org/10.4000/studifrancesi.495

\section{Questo documento è stato generato automaticamente il 17 settembre 2020.}

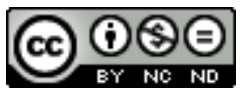

Studi Francesi è distribuita con Licenza Creative Commons Attribuzione - Non commerciale - Non opere derivate 4.0 Internazionale. 


\title{
Honoré de Balzac, Il Padre Goriot
}

\author{
Marco Stupazzoni
}

\section{NOTIZIA}

HONORÉ DE BALZAC, Il Padre Goriot, traduzione e cura di Cesare DE MARCHI, in appendice il «catalogo» delle opere e la «Premessa» alla Comédie humaine, Milano, Feltrinelli, [2004] 2013, «Universale Economica - I Classici», pp. xxIv-263.

1 Giunto alla terza edizione, il testo di questa traduzione italiana del capolavoro balzachiano si fonda su quello della seconda edizione Werdet (maggio 1835) con la sola eccezione della suddivisione in capitoli che rimanda alla prima edizione del romanzo pubblicata nel mese di marzo dello stesso anno. Come indicato nel frontespizio, il volume propone all'attenzione dei lettori due documenti essenziali per comprendere $\mathrm{i}$ fondamenti estetico-programmatici di Balzac in riferimento al sistema-Comédie humaine: ci riferiamo al Catalogo stilato da Balzac stesso nel 1845 (Appendice 1, pp. 239-246) e all'Avant-propos del luglio 1842 (Appendice 2, pp. 247-262).

2 Nell'ottimo saggio introduttivo che precede il testo de Il Padre Goriot (Un visionario appassionato, pp. V-XXI), C. DE MARCHI individua le luci e le ombre che, a suo giudizio, attraversano il tessuto narrativo del romanzo con particolare riferimento alla funzione svolta dai personaggi-protagonisti nell'economia del testo. Nel Père Goriot, romanzo «dalla trama incalzante e dalla grande teatralità delle scene principali» (p. XIII), Balzac, da romanziere assoluto quale egli è, sottopone il processo di rappresentazione del reale «alle esigenze e agli intenti del narratore» (p. xv) forzando romanzescamente la realtà. Riferendosi alla figura di Goriot, De Marchi osserva che la posizione di colui che incarna religiosamente il sentimento della paternità, e che fornisce il titolo al romanzo, pare essere relativamente marginale rispetto al ruolo assunto da altre figure di primo piano, come, ad esempio, quella di Rastignac. I difetti introspettivi nella rappresentazione del personaggio Eugène conducono De Marchi a precisare il carattere ambiguo di questa figura e a rilevare che «le vicende interiori di Eugène, pur disponendosi in una struttura narrativa robusta, non danno luogo a un romanzo di formazione» poiché, 
mancando il soggetto unificante, «non c'è la personalità che muta, c'è soltanto il mutamento» (p. XII). 